Research

\title{
Pineal proteins upregulate specific antioxidant defense systems in the brain
}

Vijay K. Bharti* and R. S. Srivastava

Neurophysiology Laboratory; Division of Physiology and Climatology; Indian Veterinary Research Institute; Izatnagar (U.P.), India

Key words: antioxidants, brain, buffalo pineal proteins, enzymes, oxidative stress, rat

The neuroendocrine functions of the pineal affect a wide variety of glandular and nervous system processes. Beside melatonin (MEL), the pineal gland secretes and expresses certain proteins essential for various physiological functions. It has been suggested that the pineal gland may also have an antioxidant role due to secretory product other than MEL. Therefore, the present study was designed to study the effect of buffalo (Bubalus bubalis) pineal proteins (PP) on the antioxidant defense system in the brain of female rats. The twenty-four rats were taken in present study and were divided into four groups: control (0 day), control (28 day), vehicle control and buffalo PP. The $\mathrm{PP}$ was injected $100 \mu \mathrm{g} / \mathrm{kg} \mathrm{BW}$ intraperitoneal (i.p.) daily for 28 days. The activities of superoxide dismutase (SOD), glutathione peroxidase (GPx), catalase (CAT), glutathione reductase (GR) and reduced glutathione (GSH) concentration and the levels of lipid peroxidation (LPO) in the brain tissue were measured to assess the antioxidant systems. These enzymes protect from adverse effects of free radicals and help in amelioration of oxidative stress. Buffalo pineal proteins administration did not cause any effect on brain LPO, whereas GPx, GR and GSH were significantly $(\mathrm{p}<0.05)$ decreased. However, SOD and CAT activities were increased to significant levels than the control in PP treated rats. Our study herein suggested that buffalo (Bubalus bubalis) pineal proteins upregulates specific antioxidant defense systems and can be useful in control of various oxidative stressinduced neuronal diseases.

\section{Introduction}

Various animal and human diseases and toxicity are often associated with oxidative stress (imbalance between formation and neutralization of pro-oxidants) in different vital organs, including the brain, and are characterized by reduced activity of certain

*Correspondence to: Vijay K. Bharti; Neurophysiology Laboratory; Division of Physiology \& Climatology; Indian Veterinary Research Institute; Izatnagar-243122 (U.P.) India; Email: vijaykbharti@rediffmail.com

Submitted: 02/06/09; Revised: 03/09/09; Accepted: 03/09/09

Previously published online as an Oxidative Medicine and Cellular Longevity E-publication:

http://www.landesbioscience.com/journals/oximed/article/8361 antioxidant enzymes. ${ }^{1,2}$ These enzymes have an important role in free radical scavenging and amelioration of oxidative stress (OS). Therefore, OS has been extensively studied in many neurological diseases. Antioxidants upregulate the level of antioxidant defense systems. ${ }^{1,2}$ The pineal gland is an integral part of the central nervous system (CNS) and is considered "Regulator of Regulators" by virtue of its capability to regulate the functions of other neural and endocrine tissues to maintain homeostasis. ${ }^{3}$ The mammalian pineal gland contains a great diversity of peptides of different origins: nervous fibers (neuropeptides) of sympathetic, central or parasympathetic origin; systemic circulation (peptidergic hormones); and cells of the pineal itself release peptides with autocrine/paracrine effects. ${ }^{4}$ Pinealocytes contains proteinaceous flocculent materials; these proteinaceous materials were believed to contain active peptides, serotonin, melatonin (MEL) and other pineal indoles. ${ }^{5}$ Mammalian pineal body also secrets biologically active proteins, peptides, enzymes, having many physiological roles of pineal gland ${ }^{6-8}$ Presence of peptidergic compounds and others secretory proteins in the mammalian pineal gland have some effect that could not be ascribed to indoleamines. ${ }^{9}$ However, their complete physiological role has not been fully studied. Reports regarding the role of pineal proteins (PP) are scarce, but a few studies revealed these proteins as presumptive pineal hormones. ${ }^{10,11}$ Since then it has been linked with some of the pineal function. ${ }^{6}$ The present study will further substantiate the physiological role of PP on antioxidant defense systems. In this study, we used buffalo PP as our agent since we have previously published with this reagent. Our earlier findings also revealed that these buffalo PP and peptides have certain physiological functions viz. immunopotentiation, ${ }^{12}$ heat stress, ${ }^{13}$ amelioration of fluoride-induced OS and apoptosis. ${ }^{8}{ }^{814}$ These proteins have a geroprotective effect which might be due to their free radical scavenging ability and thus antioxidant properties. ${ }^{15,16}$ These findings support a concept that PP have a great impact on physiology of the animal. Based on our earlier laboratory findings and others, the present study was undertaken with the hypothesis that buffalo pineal proteins may have a significant physiological role on the modulation of certain antioxidant defense systems. In light of these facts, this study was designed to evaluate the effect of PP on enzymatic and non-enzymatic antioxidant defense systems in the rat brain. 


\section{Results}

All the comparisons were made between vehicle and PP with control animals (28 day). Level of LPO was unaffected in the PP and vehicle treated rats as compared with the control ( 0 and 28 day) (Table 2, Fig. 2). Vehicle has no effect on CAT activity and did not change in comparison to control animals (Fig. 1). However, PP has enhanced the CAT activity (13.56\%) as compared with control rats (Table 2, Fig. 1). Glutathione peroxidase activity in the brain was significantly $(\mathrm{p}<0.05)$ decreased in vehicle $(-11.60 \%)$ as well as PP (-16.52\%) administered animals (Table 2, Fig. 1) as compared to control (28 day) animals.

We recorded dramatic increase of SOD activity in vehicle (121.19\%) and PP (167.93\%) exposed rats (Table 3, Fig. 2). Surprisingly, GR (-32.46\%) and GSH (-27.15\%) levels were significantly $(\mathrm{p}<0.05)$ decreased in $\mathrm{PP}$ treated rats (Table 3, Fig. 2). Vehicle administration also resulted decrease of GR $(-12.65 \%)$ activity as compared to control (Fig. 1). However, GSH concentration was unaffected in vehicle treated group as compared to control (Table 3, Fig. 2).

\section{Discussion}

This study shows the importance of the physiological role of buffalo PP in the well being of an animal for maintaining the brain OS. Nevertheless, we have demonstrated that in the rat brain, PP has an important ability to increase a certain brain antioxidant defense system. The brain and nervous system are prone to OS, and also inadequately equipped with an antioxidant defense system to prevent 'ongoing' oxidative damage. ${ }^{24}$ In addition to this, the brain consumes large quantities of oxygen that contributes to the formation of reactive oxygen species (ROS).

Several enzymes are important in antioxidative defense as they metabolize either free radicals or reactive oxygen intermediates to no-radical products. ${ }^{25}$ In the present study, PP administration could not upregulate GPx, GR and GSH levels, although it did enhance the CAT and SOD activities. These effects of PP on certain antioxidant enzymes indicate the enzyme and organs physiological status specific action of buffalo PP. The different physiological functions and tissue-dependent responses of antioxidant enzymes have been previously observed. These differences might be due to the metabolic rate of these tissues and also an indication of a compensatory adaptive mechanism to defend the gradual onset of OS. The observations of daily and seasonal variations in their pineal content associated with specific daily and seasonal modulation of pineal metabolism support a physiological function of these neuropeptides in the expression of the daily and annual MEL secretion. ${ }^{26,27}$

These peptides influence the pineal serotonin, $\mathrm{N}$-acetyltransferase activity and MEL synthesis. ${ }^{28}$ Hence, it is speculated that PP exerts its antioxidant effects indirectly, via induction of anti-oxidant proteins that catalytically convert free radicals and ROS into harmless water via MEL secretion. Therefore, this physiological basis of MEL synthesis might be influenced by PP administration and upregulates certain antioxidant enzymes. ${ }^{8}$ Therefore, PP has two effects, one direct and second indirectly via its influence on MEL

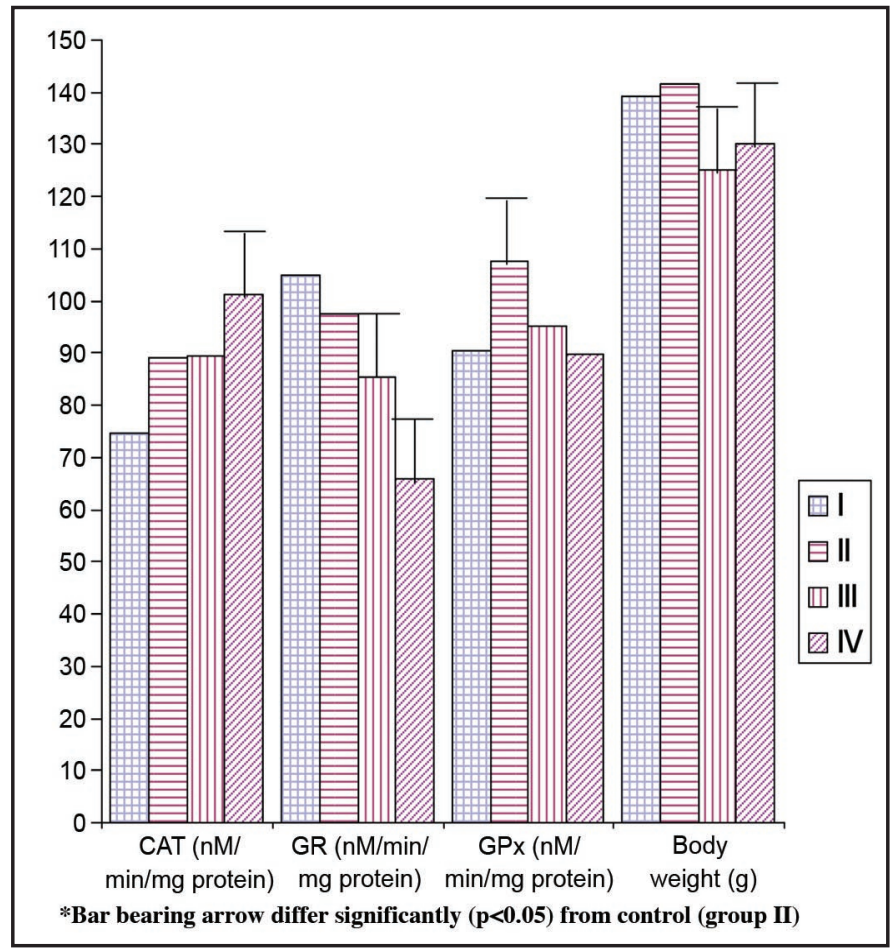

Figure 1. Effect of different treatments on certain oxidative stress indicating enzymes in the brain of female rates. ${ }^{*}$ : Day 0 Control, II: day 28 control, III: Vehicle control, IV: pineal proteins. **Bar (denotes mean values) bearing arrow differ significantly $(p<0.05)$ from control (group II). *** Lipid peroxidation (LPO), superoxide dismutase (SOD), catalase $(C A T)$, glutatione reductase $(G R)$, glutathione peroxidase $(G P x)$ and reduced glutathione (GSH).

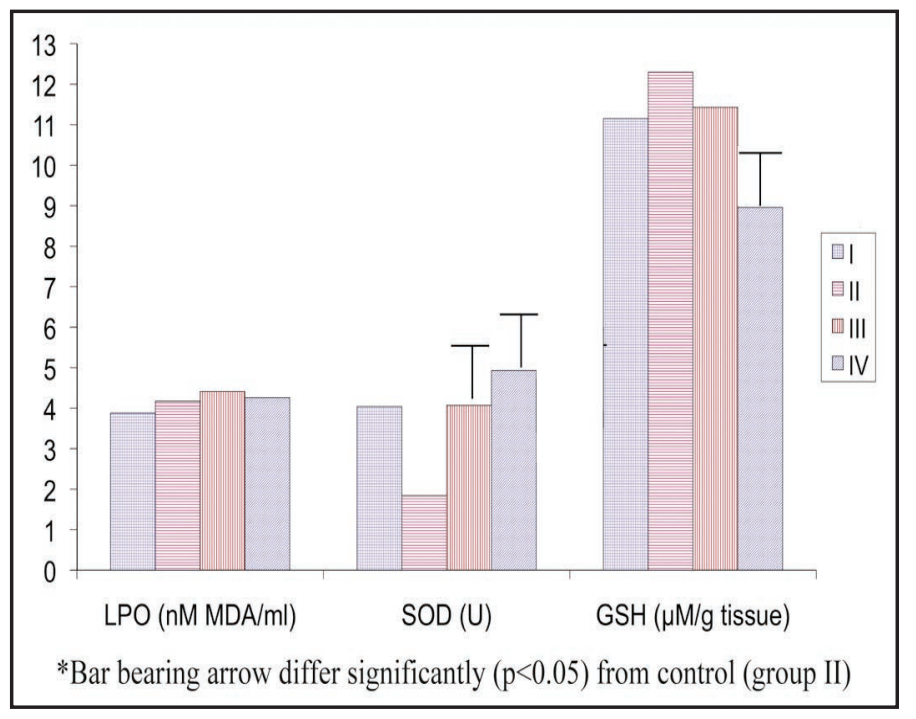

Figure 2. Effect of pineal proteins on lipid peroxidation (LPO), superoxide dismutase (SOD) and reduced glutathione (GSH) in the brain of female rats. *I: Day 0 Control, II: day 28 control, III: Vehicle control, IV: pineal proteins. * Bar (denotes mean values) bearing arrow differ significantly ( $\mathrm{p}$ $<0.05$ ) from control (group II). ${ }^{* * *}$ Lipid peroxidation (LPO), superoxide dismutase (SOD), catalase (CAT), glutatione reductase (GR), glutathione peroxidase (GPx) and reduced glutathione (GSH). 
Table 1 Distribution of experimental rats to different treatments

\begin{tabular}{|c|c|c|c|c|c|}
\hline Groups & & Body weight (g) & Treatments & Dose & Route of administration \\
\hline I & $C-O D$ & $139.16 \pm 3.51^{b}$ & Drinking water & Ad libitum & Oral \\
\hline ॥ & $C-28 D$ & $141.66 \pm 3.57^{b}$ & Drinking water + Normal saline & Ad libitum & Oral, Intra peritoneal \\
\hline IV & PP & $130.00 \pm 3.41^{a}$ & Pineal proteins (PP) & $100 \mu \mathrm{g} / \mathrm{kg} \mathrm{BW}$ & Intra peritoneal \\
\hline
\end{tabular}

Means $(\mathrm{n}=6$; means $\pm \mathrm{SE}$ ) bearing different superscripts ( $\mathrm{a}, \mathrm{b})$ differ significantly $(\mathrm{p}<0.05)$ in a column. $\mathrm{C}-0 \mathrm{D}$, Day 0 Control; $(-28 \mathrm{D}$, day 28 control; Veh, Vehicle control; PP, pineal proteins.

Table 2 Effect of different treatments on lipid peroxidation (LPO), catalase (CAT) and glutathione peroxidase (GPx) in the brain of female rats

\begin{tabular}{lcccccc} 
Group & & \multicolumn{4}{c}{ Parameters } \\
IPO (nM MDA/ml) & \% Change & CAT (nM/min/mg protein) & \% Change & GPx (nM/min/mg protein) & \% Change \\
I & $3.88 \pm 0.120^{a}$ & $6.95(-)$ & $74.75 \pm 6.20^{a}$ & $16.14(-)$ & $90.62 \pm 4.90^{a}$ & 15.69 \\
II & $4.17 \pm 0.150^{a}$ & - & $89.14 \pm 5.19^{a}$ & - & $107.49 \pm 7.79 b$ \\
III & $4.41 \pm 0.095^{a}$ & 5.75 & $89.54 \pm 4.72^{a}$ & 0.45 & $95.02 \pm 6.03^{b a}$ \\
IV & $4.26 \pm 0.170^{a}$ & 2.16 & $101.23 \pm 5.06^{b}$ & 13.56 & $89.73 \pm 4.49^{a}$ \\
\hline
\end{tabular}

Means $(\mathrm{n}=6$; means $\pm \mathrm{SE})$ bearing different superscripts $(\mathrm{a}, \mathrm{b})$ differ significantly $(\mathrm{p}<0.05)$ in a column. $(-)$ percentage decrease and values not having this sign indicate percentage increase.

Table 3 Effect of pineal proteins on superoxide dismutase (SOD), glutathione reductase (GR) and reduced glutathione (GSH) in the brain of female rats

\begin{tabular}{|c|c|c|c|c|c|c|}
\hline Group & SOD (U) & $\%$ Change & $\begin{array}{c}\text { Parameters } \\
\text { GR (nM/min/mg protein) }\end{array}$ & $\%$ Change & GSH ( $\mu \mathrm{M} / \mathrm{g}$ tissue) & $\%$ Change \\
\hline II & $1.84 \pm 0.130^{a}$ & - & $97.69 \pm 4.56^{c}$ & - & $12.30 \pm 0.59 b$ & - \\
\hline IV & $4.93 \pm 0.650^{b}$ & 167.93 & $65.98 \pm 3.89 a$ & $32.46(-)$ & $8.96 \pm 0.56^{a}$ & $27.15(-)$ \\
\hline
\end{tabular}

Means $(n=6$; means $\pm S E)$ bearing different superscripts $(a, b$ and $c)$ differ significantly $(p<0.05)$ in a column. $(-)$ percentage decrease and values not having this sign indicate percentage increase.

synthesis. Thus, by activating cellular defenses, PP can ameliorate oxidative damage far beyond its capacity as a molecular radical scavenger.

We observed lower activities of GPx, GR and concentration of GSH, while the level of LPO was unaffected in PP-treated rats. The probable reason for reduction of GSH content could be due to inhibition of GR activity. In addition to this, the decrease in the levels of certain OS related parameters in the brain observed in our study might be due to an absence of any potent OS inducible agents in healthy animals. Therefore, it has poor effect on induction of an all body antioxidant defense system. We earlier reported an ameliorating effect of PP through upregulation of CAT, GR, GPx and GSH in fluoride-induced OS in the rats. ${ }^{8}$

Catalase causes reductive degradation of $\mathrm{HOOH}$ into water and oxygen. It is well known that the protection of cells from oxidative damage can be accomplished through non-enzymatic and enzymatic antioxidant systems. ${ }^{29}$ Superoxide dismutase and GPx play an important role in the metabolism of ROS in the brain. ${ }^{30}$ The antioxidase SOD catalyzes the dismutation of $\mathrm{O}^{2}$ into $\mathrm{HOOH}$ and $\mathrm{O} 2 .{ }^{31}$ High SOD activities are observed in the brain tissues of rats. There may be two possibilities for induction of SOD activities: the increase in SOD activity is elicited by the antioxidative activity of PP, which is mediated by changes in SOD gene expression. Some of the component of PP might have crossed the blood-brain barrier and modulated antioxidant defense system in the brain. These results clearly show that PP have antioxidant role, as it upregulates specific antioxidant defense systems and therefore could prevent a variety of OS-induced diseases.

\section{Methods}

The present study was conducted at Neurophysiology Laboratory of the Indian Veterinary Research Institute, Izatnagar (U.P.), India. This is located at an altitude of 172 meters above the mean sea level at latitude of $28.20^{\circ}$ North and longitude of $79.24^{\circ}$ East. The climate is subtropical. The Institutional Animal Ethics Committee and Committee for the Purpose of Control and Supervision of Experiments on Animals duly approved all the procedures, conducted on the experimental animals.

Chemicals. Chemicals used in the study were of analytical grade from HiMedia, Loba Chemie (Mumbai, India); Sigma Chemical Co., St. Louis; USA; SRL Chemicals, India.

Experimental animals. The present study was carried out in adult female Wistar rats (125-142 g body weights), were taken from the Laboratory Animal Resource (LAR) Section of the Institute. Either sex of animal could be use for antioxidant study; however we selected female rats, as we were also studied effect 
of PP on ovarian hormones in another experiment. After an acclimatization period of one week, they were weighed and randomly assigned to various groups (Table 1 ). Animal room temperature and relative humidity were set at $21 \pm 2^{\circ} \mathrm{C}$ and $50 \pm 10 \%$, respectively and lighting was controlled to give $12 \mathrm{~h}$ light and $12 \mathrm{~h}$ darkness. All the experimental animals were housed in polypropylene cages and rice husk was used as the nesting material. All the rats had free access to laboratory animal diet and clean water. The animals were checked daily for the health and husbandry conditions.

Experimental design. The experimental design for the present study, including various groups, doses, route and duration of treatment made has been presented in Table 1 . White crystalline buffalo PP was procured from Neurophysiology Laboratory, Division of Physiology \& Climatology, IVRI, Izatnagar. We used buffalo PP as our agent since we have previously published with this reagent. Before the start of experiment appropriate dose of pineal proteins were optimized in pilot trial. Dose of pineal proteins was calculated based on animal body weight and thereafter, they were dissolved in vehicle (normal saline) and administered (daily for 28 day) intraperitoneally (i.p.).

Sample collection. Daily observations were taken for the behavioral changes throughout the experimental period. The rats were euthanized-using ether and brain was collected on zero day and at the end of experiment (28 day). Thereafter, cleaned, rinsed in chilled saline, blotted and weighed and kept at $-20^{\circ} \mathrm{C}$. Stored brain samples were partially thawed and $200 \mathrm{mg}$ of sample was weighed and taken in $2 \mathrm{ml}$ of ice-cold saline for various parameters related to antioxidant defense system. Another $200 \mathrm{mg}$ of sample was weighed separately and taken in $2 \mathrm{ml}$ of $0.02 \mathrm{M}$ EDTA (ethylenediaminetetraacetic acid) for GSH (reduced glutathione) estimation. Organ homogenates were prepared using IKA homogenizer (Germany), under ice-cold condition. Homogenates were collected and centrifuged for $10 \mathrm{~min}$ at 3,000 rpm. Thereafter, cell free supernatant were separated and transferred to precooled microfuge tube in aliquot and stored at below $-20^{\circ} \mathrm{C}$. These supernatants were used for estimation of various parameters.

Analytical procedures. Cell free supernatant of tissues homogenates were taken for the analysis of total proteins, lipid peroxidation (LPO) and different oxidative related enzymes viz. catalase (CAT), superoxide dismutase (SOD), glutathione peroxidase (GPx) and glutathione reductase (GR) activity, as well as non-enzymatic reduced glutathione (GSH) concentration. These enzymatic and non-enzymatic antioxidant defense systems are essential to combat OS in the body. These parameters are upregulated by antioxidants supplementation. Therefore, to test antioxidant properties of PP, we examined these parameters. Absorbance of all the tissue biochemical estimations was read, using Double Beam UV-VIS Spectrophotometer (UV 5704 SS, ECIL, India).

Lipid peroxidation (LPO). Membrane peroxidative damage due to free radicals was determined in terms of malondialdehyde (MDA) production by the method of Rehman. ${ }^{17}$

Catalase (CAT). Activities of catalase enzymes were estimated by spectrophotometric method as described by Bergmeyer ${ }^{18}$ and were expressed as $\mathrm{nM} \mathrm{H} \mathrm{H}_{2} \mathrm{O}_{2}$ utilized $/ \mathrm{min} / \mathrm{mg}$ protein.

Superoxide dismutase (SOD). Superoxide dismutase activities were estimated as per the method described by Madesh and Balasubramanian. ${ }^{19}$ It involves generation of superoxide by Pyrogallol autoxidation and the inhibition of superoxide-dependent reduction of the tetrazolium dye MTT [3-(4-5 dimethyl thiazol)2,5diphenyl tetrazolium bromide] to its formazan, measured at 570 $\mathrm{nm}$. The reaction was terminated by the addition of dimethyl sulfoxide (DMSO), which helps to solubilize the formazan formed. Activities was expressed as SOD Units [one unit of SOD is the amount $(\mu \mathrm{g})$ of protein required to inhibit the MTT reduction by $50 \%]$.

Glutathione reductase (GR). The enzyme activities were assayed by the method of Goldberg and Spooner. ${ }^{20}$ The reaction mixture contained phosphate buffer (0.12 M, pH 7.2), EDTA (15 mM) and GSSG (oxidized glutathione) $(65.3 \mathrm{mM})$. To these cells free supernatant was added and then incubated at room temperature. Thereafter, NADPH (nicotinamide adenine dinucleotide phosphate) $(9.6 \mathrm{mM})$ was added and immediately decrease in $\mathrm{OD} / \mathrm{min}$ was recorded at $340 \mathrm{~nm}$ for three minutes. The enzyme activity has been expressed as nM NADPH oxidized to NADP/mg of protein/ min by using the molar extinction coefficient of $6,200 / \mathrm{M} / \mathrm{cm}$ at $340 \mathrm{~nm}$.

Glutathione peroxidase (GPx). Glutathione peroxidase activities in brain tissues were determined by the method of Paglia and Valantine. ${ }^{21}$ The reaction mixture contained phosphate buffer ( $\mathrm{pH}$ 7.0) containing EDTA; NADPH; GSH; sodium azide; GR. The reaction was initiated by the addition of $\mathrm{H}_{2} \mathrm{O}_{2}$ to the reaction mixture. The change in the absorbance was read at $540 \mathrm{~nm}$ at minute interval for four minutes. The enzyme activity was expressed as nM of substrate (NADPH) utilized/min/mg protein.

Reduced glutathione (GSH). The concentration of GSH in brain was estimated by evaluating free-SH groups, using DTNB (5-5'-dithiobis, 2-nitrobenzoic acid) method described by Sedlak and Lindsay. ${ }^{22}$ For GSH estimation, $10 \%$ tissue homogenates were made in $0.02 \mathrm{M}$ EDTA.

Protein assay. Protein contents in brain homogenates were determined and calculated by the method of Lowry et al. ${ }^{23}$

Statistical analysis. Differences between groups were statistically analyzed by one-way ANOVA, and the differences between the means of groups were separated by least significant difference (LSD) test. All data were presented as mean \pm standard error. Significant differences were determined at the levels of $\mathrm{p}<0.05$. A computer program (SPSS 10.01, SPSS Inc., Chicago, IL, USA) was used for statistical analysis.

\section{Conclusions}

In conclusion, these results indicate that GSH, GPx and GR levels are decreased upon PP administration. However, buffalo PP enhanced certain enzymatic antioxidant defense systems (SOD and CAT) in the brain of rats. Hence, buffalo PP may protect against free radical-mediated oxidative changes in brain tissue by boosting specific antioxidant defense systems. Therefore, it may find utility as a pharmacological agent in preventing and treating all disorders in which free radical formation and OS is a pathogenic factor. However, systemic in depth studies in this direction are required to know the exact molecular mechanism of its antioxidant role. 


\section{Acknowledgements}

Research grant in the shape of Institute Senior Research Fellowship to the first author and facilities provided by Indian Veterinary Research Institute for conducting this study is duly acknowledged. I also acknowledge the tireless efforts of our lab and animal shed assistants.

\section{References}

1. Chinoy NJ, Patel TN. The influence of fluoride and/or aluminium on free radical toxicity in the brain of female mice and beneficial effects of some antidotes. Fluoride 2000; 33:8.

2. Georgieva NV. Oxidative stress as a factor of disrupted ecological oxidative balance in biological systems-A review. Bulgarian J Vet Med 2005; 8:1-11.

3. Romijn HJ. The pineal: A tranquillizing organ. Life Sci 1978; 23:2257-74.

4. Pevet $P$. The different classes of proteic and peptidergic substances present in the pineal gland, in The Pineal Gland and its Endocrine Role (Axelrod J, Fraschini F, Velo GP, eds), Plenum Press, London 1983; 113-59.

5. Vollrath. The effect of treatment with melatonin upon the ultra structure of the mouse pineal gland: A quantitative study. Brazilian J Biol 1984; 61:679-84.

6. Blask DE, Vaughan MK, Reiter RJ. In the pineal gland. R. Relkin, Ed., Elsevier, Amsterdam 1983; 201-24.

7. Benson B. Bovine pineal tripeptide threonylseryllysine retards puberty in female rats. J Pineal Res 1989; 6:351-7.

8. Bharti VK, Srivastava RS. Fluoride-induced oxidative stress in rat's brain and its amelioration by buffalo (Bubalus bubalis) pineal proteins and melatonin. Biol Trace Elem Res 2009; DOI: $10.1007 / \mathrm{s} 12011-009-8320-2$.

9. Kappers JA. Localization of indoleamine and protein synthesis in the mammalian pineal gland. J Neural Transmi 1978; 13:13-24.

10. Benson B, Ebels I. Pineal peptides. J Neural Transmi 1978; 13:157-74.

11. Reiter RJ. The pineal gland and its hormones in the control of reproduction in mammals. Endocrine Rev 1980; 1:109-31.

12. Ramasamy M. Studies on bubaline pineal proteins/peptides below $20 \mathrm{kDa}$ and their immunopotentiation in guinea pigs. Ph.D. Thesis. Indian Veterinary Research Institute, Izatnagar, India 2006.

13. Sejian V. Studies on pineal-adrenal relationship in goats (Capra hircus) under thermal stress. Ph.D. Thesis. Indian Veterinary Research Institute, Izatnagar, India 2006.

14. Bharti VK. Studies on buffalo (Bubalus bubalis) pineal proteins on fluoride-induced oxidative stress and apoptosis in rats. Ph.D. Thesis. Indian Veterinary Research Institute, Izatnagar, India 2008.

15. Anisimov VN, Khavinson VK, Morozov VG. Twenty years of study on effects of pineal peptide preparation: Epithalamin in experimental gerontology and oncology. Ann N Y Acad Sci 1994; 719:483-93.

16. Korkushko O, Khavinson V, Shatilo V, Antonyuk SI. Geroprotective effect of epithalamine (pineal gland peptide preparation) in elderly subjects with accelerated ageing. Bulletin Exper Biol Medic 2006; 142:356-9.

17. Rehman S. Lead-induced regional lipid peroxidation in brain. Toxicol Letter 1984; 21:333-7.

18. Bergmayer HU. UV method of catalase assay. In: Methods of Enzymatic Analysis. Volume III ${ }^{\text {rd }}$. Weinheim Deer field Beach, Florida, Bansal 1983; 273.

19. Madesh M, Balasubramanian KA. Microtitre plate assay for superoxide dismutase using MTT reduction by superoxide. Indian J Biochem Biophy 1998; 35:184-8.

20. Goldberg DM, Spooner RJ. Glutathione reductase. Bergmeyer J, Grassi M, eds. Methods in Enzymatic Analysis. VCH Weinheim, Germany 1983; 258-65.

21. Paglia DE, Valentine WN. Studies on the quantitative and qualitative characterization of erythrocyte glutathione peroxidase. J Lab Clin Med 1967; 70:158-69.

22. Sedlak J, Lindsay RH. Estimation of total, protein-bound and nonprotein sulfhydryl groups in tissue with Ellman's reagent. Analyt Bioche 1968; 25:192-5.

23. Lowry OH, Rosebrough NJ, Farr AI, et al. Protein measurement with the Folin phenol reagent. J Biol Chem 1951; 193:265-75.

24. Halliwell B. Oxidative stress and neurodegeneration: Where are we known. J Neurochem 2006; 97:1634-58.

25. Breen AP, Murphy JA. Reactions of oxyl radicals with DNA. Free Radical Biol Medci 1995; 18:1033-7.

26. Shinohara K, Inouye SIT. Circadian variations of neuropeptide Y-like immunoreactivity in the rat pineal gland. Neuroreport 1994; 5:1262-4.

27. Moller M, Masson-Pevet M, Pevet P. Annual variations of the NPYergic innervation of the pineal gland of the European hamster (Cricetus cricetus). A quantitative immunohistochemical study. Cell Tissue Res 1998; 291:421-3.

28. Nowicki M, Lewczuk B, Kosacka J, et al. Pituitary adenylate cyclase-activating polypeptide-immunoreactive nerve fibers in the pig pineal gland. Folia Histochem Cytobiol 2003; 140:149-50.

29. Aitken RJ, Roman SD. Antioxidant systems and oxidative stress in the testes. Oxidative Med Cellular Longevity 2008; 1:14-5.
30. Tan DX, Manchester LC, Terron MP, et al. One molecule, any derivatives: a neverending interaction of melatonin with reactive oxygen and nitrogen species. J Pineal Res 2007; 42:28-42.

31. Sinet PM, Garber P. Inactivation of human $\mathrm{Cu}-\mathrm{Zn}$ superoxide dismutase during exposure to $\mathrm{O}_{2}$ and $\mathrm{H}_{2} \mathrm{O}_{2}$. Archive Biochem Biophy 1981; 212:411-6. 


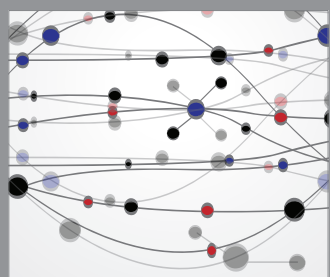

The Scientific World Journal
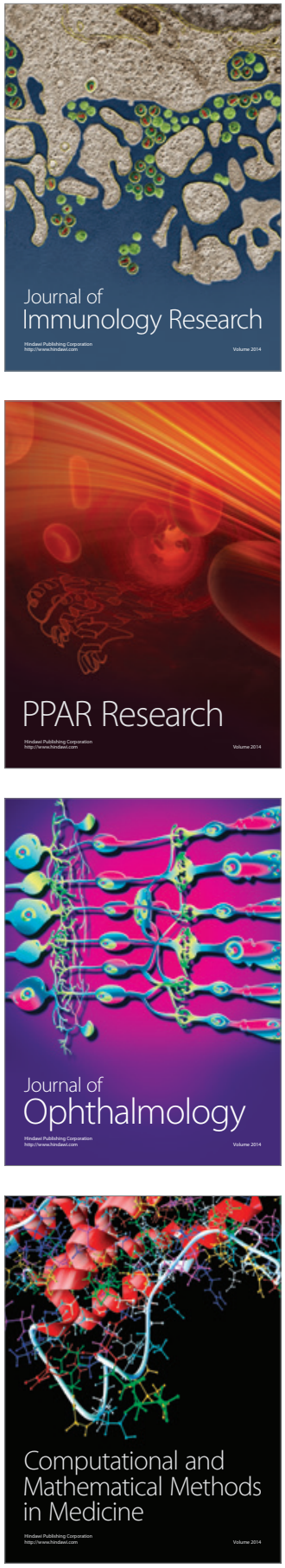

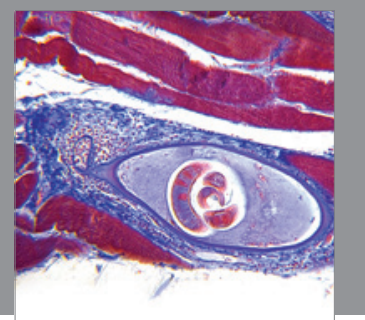

Gastroenterology

Research and Practice
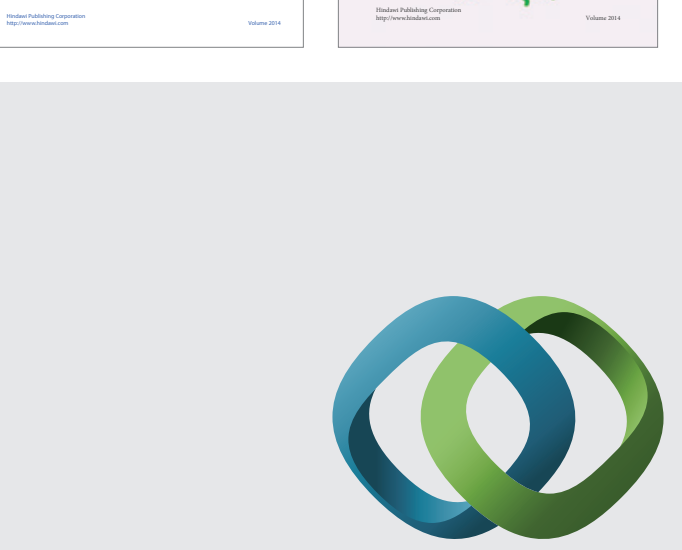

\section{Hindawi}

Submit your manuscripts at

http://www.hindawi.com
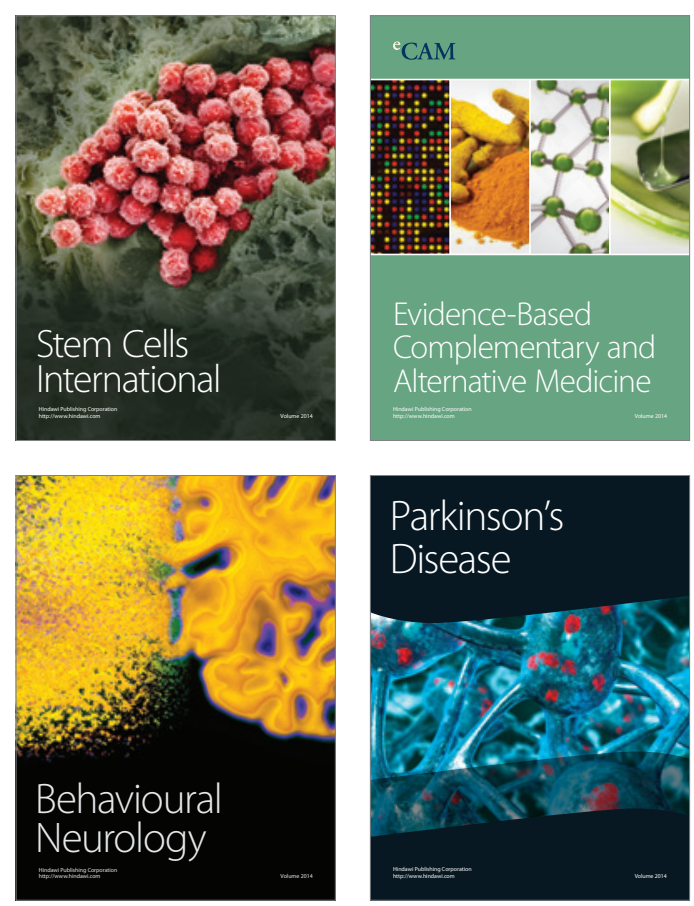

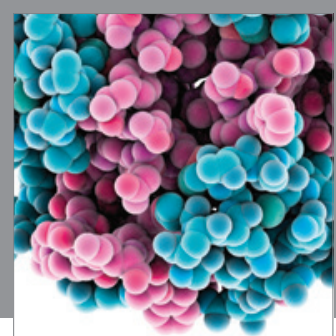

Journal of
Diabetes Research

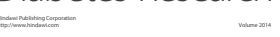

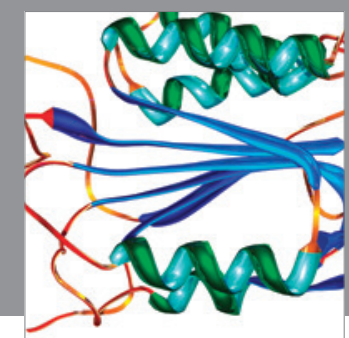

Disease Markers
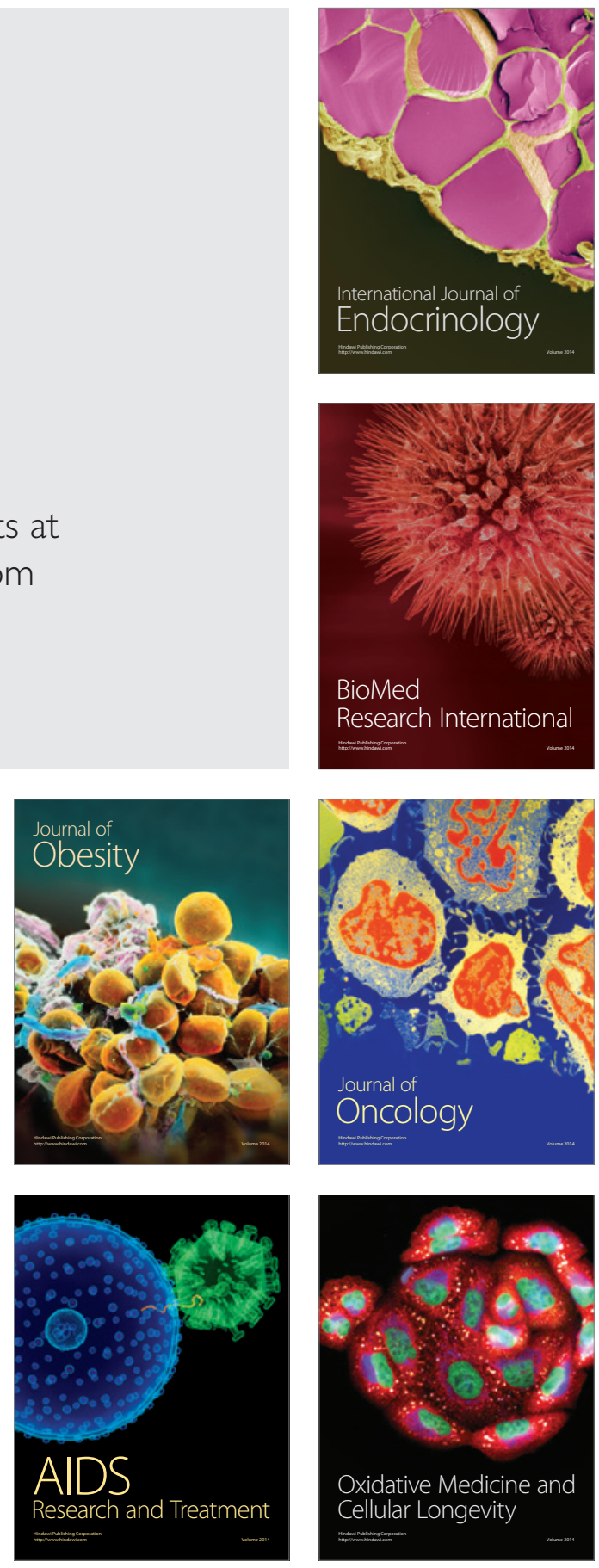